\title{
Educação online colaborativa: implicações teórico-metodológicas de uma nova modalidade de ensino e aprendizagem
}

Online Collaborative Education: Theoretical and methodological implications of a new mode of teaching and learning

Bruno José Betti Galasso*

Denise Trento Rebello de Souza ${ }^{* *}$

Resumo

$\mathrm{O}$ artigo problematiza alguns elementos básicos da educação online. Considera que a vida nas sociedades contemporâneas é atravessada pelas Tecnologias Digitais de Comunicação e Informação (TDIC) e que, portanto, a educação se beneficiaria desse suporte na revisão de seu modo de operar. Parte de pesquisa concluída recentemente sobre educação online para apresentar alguns dos elementos essenciais dessa modalidade de ensino, tais como trabalho colaborativo, interação, virtualização e hipermídia, bem como para refletir sobre características e sobre o lugar docente na educação online.

Palavras-chave: educação online; trabalho colaborativo; hipermídia.

\section{Abstract}

The paper seeks to problematize some of the basic elements of online education. It recognizes that life in contemporary societies is permeated by Digital Information and Communication Technologies (DICT) and that, therefore, education would benefit from including these new supports in a revision of its manner of operating. It departs from a recently concluded study on online education, and introduces some of the essential elements of this modality of teaching, such as collaborative working, interaction, virtualization and hypermedia, whilst reflecting upon the characteristics of online education and upon the role of teachers in it.

Keywords: online education; collaborative work; hipermidia.

Na contemporaneidade, as revoluções tecnológicas engendram-se em todos os domínios da atividade humana, de modo que tecnologia e sociedade

*Doutor em Educação. Faculdade de Educação, Universidade de São Paulo (USP). brunogalasso@ uol.com.br

${ }^{*}$ Departamento de Filosofia da Educação e Ciências da Educação, Faculdade de Educação, Universidade de São Paulo (USP).dtrento@uol.com.br 
precisam ser concebidas necessariamente em suas imbricações. Com o crescente desenvolvimento tecnológico experimentado nas últimas duas décadas, a quantidade de informação e de conhecimento, assim como as tecnologias que os viabilizaram, possibilitaram a emergência de métodos, conteúdos e formas de interação alternativos àqueles tradicionalmente praticados no âmbito educacional.

Nesse contexto, as tecnologias modernas vêm se caracterizando por uma dinâmica que afeta o modo de produzir e partilhar informações e conhecimento, bem como a própria constituição dos indivíduos, sua subjetividade e seu modo de relacionar-se com os outros e com o mundo.

No final do século passado, quando se vislumbrava o futuro transformado pelas Tecnologias Digitais de Comunicação e Informação (TDIC), Toffler (1990, p.44) ponderava que, por mais de três séculos, as nações industrializadas travaram uma luta política em torno da distribuição da riqueza, procurando estabelecer hierarquias. Mas, "seja qual for a distância que separa os ricos dos pobres, um abismo ainda maior separa os ignorantes dos instruídos”. Apesar de todas as iniquidades de renda e riqueza, a disputa por posições de prestígio e poder vem se transformando também em um embate por distribuição e acesso ao conhecimento. Nessa nova ordem, não há como se proteger contra o abuso do poder se não tivermos a noção de como e para quem flui o direcionamento de informações contínuas caracterizado pelo ciberespaço.

Nesse sentido, a tarefa do educador ocorre num contexto social em que as transformações tecnológicas recentes trazem novos cenários e novos modos de relação que se impõem e que não podem ser ignorados. A realidade social compreende sistemas educacionais, mas também diversos outros sistemas que influenciam a educação e dela sofrem influência. Essa permeabilidade entre instituições de ensino e sociedade está na origem das complexas relações entre essas instâncias, fazendo que na escola se desenvolvam processos sociais e culturais diversos: reprodução, resistência, negociação, apropriação e transformação, entre outros. ${ }^{1}$ Assim, no âmbito desses processos se formam relações em que a diversidade de opiniões, ideias e formas de se compreender e significar o mundo se fazem presentes.

Diante desse cenário de transformações, sociedade e educação veem-se frente a inúmeros desafios para garantirem a formação de cidadãos conscientes e críticos, que tenham fortalecida a capacidade de reflexão e de participação 
nos processos culturais, sociais e econômicos das sociedades em que vivem. Essas não são tarefas simples, pois demandam, entre outras coisas, a redefinição do papel da escola bem como negociações no estabelecimento das políticas públicas que venham ao encontro da promoção de uma educação escolar acessível a um maior número de pessoas, se possível com ganhos em qualidade. Considerando que este país é de vastas proporções, com regiões bastante diferenciadas econômica e culturalmente, a educação a distância apresenta-se como uma alternativa complementar - é importante dizer - que oferece vantagens não desprezíveis. No entanto, essa modalidade de ensino ainda é implementada com ressalvas e dúvidas em relação a vários aspectos, desde técnicos e pedagógicos, até políticos e ideológicos (Keegan, 1996).

Ensinar, como afirma Freire (2011, p.96), requer apreensão da realidade. Nossa capacidade de ensinar decorre da nossa capacidade de aprender, e o aprendizado não ocorre apenas para a nossa adaptação, mas, sobretudo, para que possamos intervir na realidade de modo a transformá-la. E como a educação é uma forma de intervenção no mundo, requer também levar em consideração e respeitar os saberes dos alunos constituídos na prática comunitária e cotidiana.

Por isso, é importante notar que os hábitos, costumes e práticas cotidianas do educando vêm sendo redesenhados pelo uso das novas tecnologias. Fora do espaço escolar, o educando utiliza a linguagem em aparelhos celulares, computadores, redes sociais, blogs, twitter, jogos online, ambientes virtuais de aprendizagem, aplicativos etc. ${ }^{2} \mathrm{~A}$ interação do indivíduo com a sociedade, então, é mediada pelas TDIC, cujos signos constituintes da linguagem são predominantes no cotidiano do aluno, ocorrendo de forma rápida e frequente.

Além disso, a interação do aluno com as TDIC implica a apropriação de diversos modelos de linguagem, visual e/ou audiovisual, leitura e/ou escrita, já pertencentes ao processo histórico-cultural do educando. A adoção desses modelos por parte da educação tenderia a evitar o conflito entre os modos de aprender no espaço escolar ou fora dele minimizando dificuldades de aprendizagem nesse processo. Mas a apropriação de soluções recorrentes no passado, ou até em países tecnologicamente mais desenvolvidos, também pode ser ardilosa ao apresentar defasagem ou inadequação. Além disso, a adesão às tecnologias de informação e de comunicação na educação online não pode vir desacompanhada de uma nova perspectiva dos conceitos de comunicação, 
interação, colaboração e virtualização. As tecnologias digitais e midiáticas mais recentes continuam a transformar os conceitos e a compreensão da realidade e das relações com o saber, acarretando grandes desafios na busca da inovação pedagógica e na construção de uma educação online que leve em conta possibilidades e limitações da virtualidade.

No que diz respeito à educação online, o país vem enfrentando sérios problemas, como a descontinuidade da legislação, das políticas públicas e de financiamentos; a utilização de modelos inadequados de ensino; o alto custo dos sofisticados equipamentos importados e de softwares; a escassez de material disponível na rede em língua portuguesa; a pouca experiência de ponta, e a escassez de profissionais com experiência para criar e operar a educação online (Litto, 2006).

Mesmo assim, essa modalidade de ensino tem apresentado novos elementos significativos nos processos de ensino e de aprendizagem. Trata-se de um modelo que pode ser vivenciado e exercitado tanto como uma forma de ensino como para potencializar situações de aprendizagem mediadas por encontros presenciais (b-learning) e totalmente a distância ou híbridos (como é o caso dos semipresenciais), quando os encontros presenciais podem ser combinados com encontros mediados por algum tipo de tecnologia.

Domingues (1997) aponta para uma "integração da mente humana com as mentes de silício" e também para o fato de que a sensibilidade humana, nos últimos tempos, está se formulando em ambientes tecnologizados. Assim, a educação online surge acompanhando o contexto em que a instituição de ensino, o educador e o educando estão inseridos, levando-se em consideração que não apenas o ambiente, mas também a capacidade humana de processar informações a partir da máquina encontram-se em transformação.

Em ambientes virtuais de aprendizagem, caracterizados pela simulação ou pela disposição de objetos e ações como no real, o estudante é virtualmente capaz de estar em um ou vários pontos (nós) do ciberespaço, lendo ou vendo notícias e informações, fazendo trabalhos em grupo, jogando e visitando museus, entre outras atividades. Com isso, o estudante pode estar em vários pontos de uma rede ao mesmo tempo, sendo essa rede a representação não somente de lugares físicos e territoriais distintos, mas também a (re)apresentação de outros sujeitos (múltiplos). 
A interação e a troca estabelecidas pelo estudante, bem como a simulação e a locação de sua existência nesses ambientes são marcadas por dispositivos semióticos que contribuem para a (in)formação. Dispositivos visualmente distribuídos em uma interface hipertextual Web, que propicia e admite o erro como condição necessária à construção de autorias em processos de produção/ difusão da informação, conhecimento e aprendizagem.

Assim, na educação online, o estudante é convidado a um deslocamento de papéis assinalado por escolhas múltiplas em que pode assumir várias características de uma identidade ou "identificações sucessivas", tendendo para o afastamento cada vez maior do papel de espectador passivo, e assumindo características como marcas reais de uma personalidade (Medeiros, 2000).

Para Molina (2007, p.42) os predicados de "participativa" e "colaborativa" dizem respeito a uma ciência educativa crítica, para a qual vêm caminhando as práticas, os entendimentos e os valores educativos. A participação do aluno lhe fornece a possibilidade de experimentar sensações que perpassam a ideia de efemeridade, espacialidade e temporalidade. Em um ambiente virtual colaborativo, percebe-se o aluno no comando de seu próprio aparelho de aprendizagem, com o professor e os colegas ao lado, em uma estrutura de poder horizontal, prontos para auxiliar, incentivar e colaborar quando necessário.

\section{O TRAÇO COLABORATIVO DO ENSINO ONLINE}

Alguns autores defendem uma autêntica revolução ou mudança paradigmática com a utilização do modelo de educação online. Harasim (2000, p.47) aponta que o trabalho em rede e a convergência do campo de comunicação com o da informática transformaram-se nos motores de uma nova forma de educação, que nos conduz a uma nova estrutura, denominada de aprendizagem em rede. Nesse panorama, ressalta-se a importância de um ensino online colaborativo: "É necessário ter presente que a colaboração deve ser fomentada e construída, razão pela qual é fundamental uma análise criteriosa das aplicações que serão empregadas, de forma a utilizar, prioritariamente aquelas que promovam a colaboração".

Assim, percebe-se que as premissas que sustentavam outros modelos de formação anterior estão agora postas em causa por meio da EaD. Ou seja, as funções do professor, dos conteúdos, da própria tecnologia, assim como a 
forma de acesso à formação e a maneira como os adultos aprendem estão se modificando.

Esse novo paradigma assenta, também, na formação em rede, que apresenta como capital a possibilidade de aprender com os outros, através do intercâmbio de experiências e práticas. A educação online distingue-se paradigmaticamente de quase todos os processos que a antecederam, pois representa uma ecologia de aprendizagem: "Não se trata de mais um complemento, mas de uma tecnologia que está transformando nossas instituições de ensino e a forma como teorizamos e praticamos a educação" (Garrison; Anderson, 2005, p.169).

Nesse sentido, a educação online não pode ser confundida com uma entregadora de dados informacionais, pois é responsável pela construção da concepção compartilhada, de modo coordenado e singular. Trata-se de um processo em que os alunos interagem, compartilham e edificam o aprendizado mutuamente, por meio da construção conjunta do conhecimento, respeitando a iniciativa própria de cada aluno. $\mathrm{O}$ aprendizado que ocorre no ambiente online dispensa hierarquias e, ao contrário, se alicerça no esforço coordenado em busca de um objetivo comum.

Vale assinalar, também, que a educação online dá valor ao processo de aprendizagem coletiva, e evolui de forma mais qualitativa do que quantitativa, pois aproxima os alunos e os incentiva ao compromisso, à responsabilidade com os colegas e a determinadas ações perante o grupo, além do compartilhamento de autoridade e compromisso mútuo. Para isso, os agentes do ensino devem coordenar esforços, e manterem-se conectados de forma sincronizada. O trabalho conjunto e a ajuda mútua estimulam "a iniciativa, a atenção aos pormenores, e o empenho na atividade ... os colegas mais capazes podem facilitar a aprendizagem dos mais fracos sem serem prejudicados com isso" (Neuman; Roskos, 1997, p.17).

Dessa forma, a utilização das TDIC na educação online resulta na redefinição do que é ensinar e aprender colaborativamente. Atualmente, com as tecnologias colaborativas, se dá a interação entre pessoas através de redes de comunicação, potencializando os processos de educação. $\mathrm{O}$ quadro a seguir resume a evolução da tecnologia educacional nos últimos tempos. 


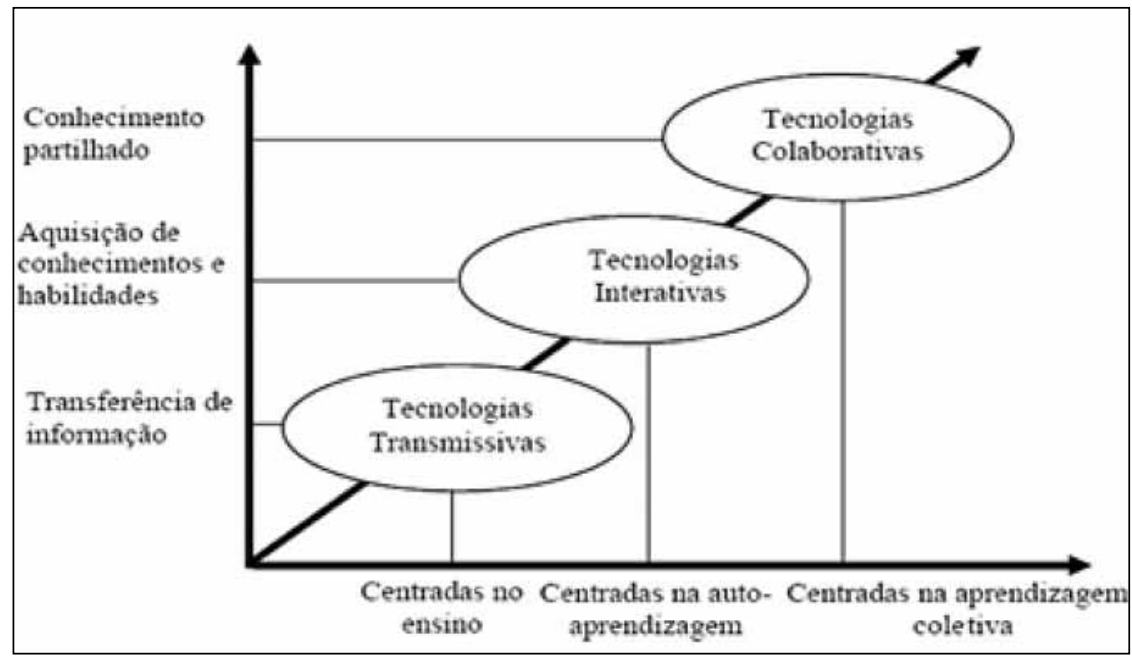

Figura 1 - Evolução das tecnologias e sua relação com a aprendizagem

Partindo das “tecnologias transmissivas”, associadas à transmissão e distribuição de conteúdos, nas primeiras fases da formação a distância, evoluiu-se para tecnologias mais interativas, que permitiam algum tipo de interação com o conteúdo por meio da máquina. Atualmente, com as "tecnologias colaborativas”, prioriza-se a interação entre pessoas através de redes de comunicação, emulando os processos de comunicação.

Com o advento das "tecnologias colaborativas", que se caracterizam pelo estabelecimento de altos níveis de interação comunicacional entre os intervenientes nos processos de formação, criam-se condições para a transformação dos processos formativos de acordo com um novo modelo mental, no qual é possível combinar independência, autonomia e colaboração.

Essa evolução tecnológica, ou seja, a transformação das tecnologias da comunicação em tecnologias da colaboração, não tem apenas a virtude de possibilitar a emergência de uma aprendizagem ativa, mas é também um incitamento para ir além da aprendizagem individual e para inscrever uma nova forma de aprendizagem em comunidade. Contudo, é necessário avançar das "tecnologias colaborativas" para a utilização colaborativa das tecnologias. A colaboração não é uma propriedade das tecnologias, mas estas podem fornecer a infraestrutura necessária para o estabelecimento de relações sociais e de trabalho, potencializando a colaboração. 
Os ambientes virtuais educativos cada vez mais vêm valorizando a colaboração, que tem sido vista não apenas como uma importante estratégia pedagógica, mas como uma filosofia do ciberespaço.

A convergência da colaboração com o potencial inovador das tecnologias parece conduzir à criação de novos espaços, com possibilidades mais alargadas de comunicação, de interação, de relacionamento social e de trabalho colaborativo, associado a novas formas de aprendizagem e formação. Independentemente de se tratar de uma evolução, de uma revolução ou de apenas mais um modelo de educação, o que aparenta é que dispomos, atualmente, da oportunidade de aprender mais, diferente e de forma diversificada.

Para o professor do ensino online, o fator colaboração contribui rompendo com a cultura de isolamento impregnada em outros modelos de educação. Cabe ao docente online ter vivência estratégica de colaboração, bem como refletir sobre as teorias metodológicas adequadas e projetos didáticos próprios para serem aplicados nos ambientes online colaborativos. As propostas educacionais, quando são dinâmicas e ativas, colaboram para que tanto docente quanto alunos experimentem outros modos de ensinar e aprender. As atividades colaborativas desenvolvidas nos ambientes virtuais de aprendizagem requerem, assim, a participação de todos os agentes do ensino. A articulação entre professor e aluno deve ser permanente, pois são eles os membros ativos da aprendizagem colaborativa, compartilhando experiências, pesquisas e descobertas na construção do conhecimento.

\section{O PROCESSO DE INTERAÇÃO NA EDUCAÇÃO ONLINE}

Na educação online, o engajamento e a participação entre os agentes do ensino e o conteúdo do curso ocorrem por meio da interação mediada pela tecnologia digital. Essa troca tem a finalidade de melhorar ou mudar o ambiente dos estudantes em relação aos objetivos educacionais, construindo conhecimentos e ampliando a compreensão do conteúdo ministrado. "É indiscutível o fato de que a internet, no contexto educacional, é uma importante difusora da educação online por sua diversidade de ferramentas de interação" (Ogliari; Souza, 2012, p.4).

Mas, para concretizar a interação no intuito de construção do conhecimento, é necessário que o curso tenha uma proposta objetiva e clara, e que o 
docente seja um profissional apto à promoção e troca de ideias. Conforme pesquisa recentemente concluída, o papel do professor não pode ser descuidado, dada sua importância, tanto no modelo presencial quanto no online, podendo ser até mais central e oneroso neste último do que no modelo anterior (Galasso, 2013, p.169).

Nesse sentido, os instrumentos de comunicação se transformam em instrumentos simbólicos de mediação, por meio dos quais o sujeito constrói seu raciocínio, dinamiza múltiplas habilidades e potencializa suas linguagens. Essa dimensão é alcançada através da experiência interativa no grupo, do componente humano e de seu processo de mediação.

Ferramentas como o fórum e os chats, apropriadas para a interação entre seus usuários, devem ser bem exploradas pelo curso online, e os alunos incentivados a usá-las para discussões e trocas de ideias. Aí se tem a mediação fundamental do professor. É preciso criar uma cultura educacional que destaque a interação na aprendizagem virtual. "Consideramos que a reflexão sobre esse tipo de atividade é fundamental para que possamos propor situações cada vez mais enriquecedoras e desafiadoras" (Torricelli; Correa, 2012, p.9).

Em ambientes virtuais de aprendizagem, a promoção da interação do aluno nas discussões é essencial para a aprendizagem. Por isso, faz-se importante que a instrução baseada na internet e no design da plataforma de ensino incluam explicitamente a interação no contexto social, uma vez que o processo de aprendizagem ocorre dentro de uma estrutura social.

Assim, é possível afirmar que a interação aluno-aluno é essencial para a educação online, pautada na colaboração. Os estudantes geralmente consideram a interação com seus pares muito valiosa e motivadora. $\mathrm{O}$ conceito de interação como a troca de informações e ideias, acrescido do diálogo que ocorre entre os alunos no curso online "contribui imensamente para uma visão centrada no aluno, focando o aprender e proporcionando a oportunidade para a negociação social do significado e da construção de conhecimentos entre os alunos" (Gunwardena; Mcisaac, 2004, p.362).

Cada estudante tem de construir seu conhecimento também por meio da interação com o conteúdo, acomodando novas informações àquelas previamente existentes no esquema cognitivo. Dessa forma, o papel do professor é apoiar e ajudar cada aluno na maneira como ele interage com o conteúdo, o que implica uma atenção mais personalizada. Para Moore (1991, p.2), a interação entre o 
aluno e o conteúdo é uma característica essencial da educação. Sem ela não pode haver educação, uma vez que é o processo intelectual da interação com o conteúdo que resulta em mudanças na compreensão do aluno, na perspectiva, ou nas estruturas cognitivas da mente do aprendiz.

Outro fator que influencia positivamente as interações online é o feedback, ou retroalimentação, que pode ser informativo e/ou corretivo. Esses tipos de comentários referem-se à informação que permite aos alunos avaliar a qualidade do seu desempenho e corrigir erros. Por isso, além de informativo ou corretivo, o feedback deve ser oportuno e preciso para evitar equívocos.

O feedback informativo inclui respostas e esclarecimentos às questões relacionadas com a logística do curso, às questões técnicas, ou o diálogo sobre as atividades do curso. Já o feedback corretivo ou de avaliação é muitas vezes considerado o tipo mais comum de feedback. Esse comentário procura dotar os alunos com informações sobre a correção de suas respostas mediante a intervenção do professor (Grooms, 2000, p.49).

\section{HIPERMÍDIA E A ARQUITETURA DA INFORMAÇÃo}

A colaboração, a interação e a boa utilização das ferramentas digitais são características próprias do contexto da hipermídia. Esse instrumento de comunicação, que reside no ambiente online, integrando ou mesclando textos, imagens, sons e vídeos, em processo de interação com o usuário, abre-se "para a experiência plena do pensamento e da imaginação, como um processo vivo que se modifica sem cessar, que se adapta em função do contexto e, enfim, joga com os dados disponíveis" (Machado, 2001, p.109).

Dá-se o nome de hipermídia aos sistemas de representação de conhecimento nos quais a informação e seus diversos elementos são articulados de diferentes modos, pois os usuários do sistema possuem diferentes expectativas. Pela hipermídia navega-se por meio de links, que conduzem a descobertas de ligações conceituais entre os temas, que se encontram em sessões que se relacionam entre si.

Caminhando pela hipermídia, no ambiente online, o estudante pode traçar seu itinerário e decidir a forma como irá percorrê-lo, mesmo que as possibilidades sejam predeterminadas. A não linearidade traduz o modo de pensar 
do ser humano. A hipermídia é um instrumento que permite àquele que o arquiteta inventar mundos e regras para a contribuição de seu enredo.

A hipermídia na educação possibilita criar ambientes de aprendizagem atraentes e motivadores. A combinação de mídias auxilia na educação, pois prende a atenção, entusiasma, entretém e ensina com maior eficiência, porque transmite as informações de várias formas, estimulando diversos sentidos ao mesmo tempo. Nisso reside o poder da informação multimidiática, em que a carga informativa é significantemente maior, os apelos sensoriais são multiplicados e isso faz com que a atenção e o interesse do aluno sejam mantidos, promovendo a retenção da informação e facilitando a aprendizagem. (Braglia, 2012, p.42)

Na educação online, a plataforma de aprendizagem deve apresentar-se ao usuário de forma simples, interativa e transparente, tendo, portanto, a capacidade de funcionar em segundo plano (como respaldo) e revelar os conteúdos, as mensagens e a interação entre os usuários do ambiente virtual.

Nesse contexto, a integração de hipermídias a ambientes virtuais de aprendizagem adota contextos semântico-cognitivos que se apoiam em estruturas de expectativa e dependem dos atos de significação. Isto é, a linguagem passa a ser vista de modo diferenciado e o pensamento é mapeado por domínios de conceitos distintos, estruturado por esquemas de imagem. Trata-se de um contexto que conta com fatores conjunturais e pragmáticos e, com isso, dá margem ao processo de criação de significados.

São muitas e variadas as consequências, em termos educativos, que advêm das particularidades apresentadas por esses sistemas, na medida em que proporcionam a criação de ambientes de aprendizagem com os quais o aprendiz pode interagir diretamente. Tal perspectiva do contexto educacional faz que $o$ ensino online se torne multirreferencial, favorecendo pesquisas e análises dos fenômenos a serem estudados nas diversas matérias, bem como a identificação e a análise das ocorrências do dia a dia.

As novas opções de ligação à escala mundial, através de modos nunca antes alcançados, proporcionam ambientes com oportunidades únicas de aprendizagem, pois o espaço considerado como distância física entre o aluno e o professor, entre dois alunos, ou entre um aluno e a fonte de recursos deixa de ser um obstáculo à aprendizagem. 
A hipermídia desenhada para ambientes virtuais de aprendizagem valoriza a metodologia centrada no aluno, exigindo ambientes online amplos, que forneçam ao aluno a sensação de espaço e de lugar para se trabalhar. Esses ambientes devem ser acolhedores como locais próprios para habitar um indivíduo ou uma comunidade de aprendizagem. Essa perspectiva construtivista gera um ambiente de aprendizagem apropriado para o trabalho em conjunto, onde os alunos possam se apoiar uns aos outros quando usam uma variedade de ferramentas e recursos de informação na perseguição de metas de aprendizagem e em atividades de resolução de problemas.

A plataforma de ensino online necessita, então, caracterizar-se em um espaço que funciona como uma interface uniforme de um sistema de informação distribuída, na qual os materiais que são objetos de aprendizagem podem ser pesquisados e mostrados de uma forma fácil e intuitiva.

Nesse sentido, faz-se necessário desenvolver um novo olhar sobre ambientes interativos mediados por computadores para buscar uma melhor qualidade dos recursos hipermidiáticos na educação. De acordo com Melo et al. (2009, p.21-22), “esses ambientes só podem auxiliar no processo de construção do conhecimento se, por trás de sua implementação, existir um profundo conhecimento da comunicação humana”. Pouco adianta recursos informáticos sofisticados, "se o aluno de cursos online, por exemplo, se sente preso e com sérias dificuldades de interagir, tirar dúvidas com seus tutores".

Desse modo, os ambientes online de educação podem constituir-se em espaços educativos flexíveis, que são ao mesmo tempo fontes de informação e de comunicação, proporcionando aos professores e estudantes condições para interagirem em sincronia ou assincronicamente, de forma bidirecional ou multidirecional, em uma sala de aula virtual. As tecnologias de suporte aos ambientes online constituem uma plataforma de ensino e aprendizagem que uniformiza o acesso a todos os serviços disponíveis, criando no usuário a visão de um sistema de informação universal.

Com a arquitetura da informação empregada no desenvolvimento de plataformas de gestão de aprendizagem, como, por exemplo, o WebCT, o Blackboard e o Moodle, que permitem a gestão, a localização e o acompanhamento dos trabalhos desenvolvidos pelos alunos, a Web tornou-se um meta-ambiente universal de aprendizagem. 


\section{O CONECTIVISMO}

O conectivismo é uma teoria de aprendizagem que, se aplicada adequadamente, tem potencial para melhorar significativamente a educação online por meio da revisão das perspectivas de ensino, gerando uma mudança maior no processo de educação centrado no estudante. A teoria permite aos professores reduzirem o controle de conteúdo do curso de maneira positiva, ou seja, desviando o foco da tradicional aula expositiva e proporcionando aos estudantes a iniciativa de localizar, apresentar e entender o sentido do conhecimento relevante. Assim, quando o conhecimento deixa de estar centrado em especialistas (professor), o conteúdo e as conversas passam a ser contínuos, e a aprendizagem pode atingir todos os participantes da aula, incluindo o professor.

Baseado em suas pesquisas para desenvolver essa nova teoria, Siemens (2003) aponta que as teorias de aprendizagem existentes não levam em conta a natureza mutável da aprendizagem e dos alunos, devida à influência dos avanços tecnológicos. Dessa forma, o conectivismo surge como a integração de princípios explorados pelo caos, redes e teorias da complexidade e auto-organização. O autor descreve o aprender online como "confuso, caótico, social, colaborativo e conectado a outras atividades e interesses. A educação formal, ao contrário... [é] artificial e estruturada” (Siemens, 2003). Em seu trabalho "Conectivismo: uma teoria de aprendizagem para a era digital", Siemens (2004, p.145) descreve os seguintes princípios do conectivismo:

- A aprendizagem e o conhecimento estão apoiados na diversidade de opiniões.

- A aprendizagem online é um processo de conectar nós especializados com fontes de informação.

- A aprendizagem pode residir em dispositivos não-humanos (o que pode ter dois significados: ferramentas tecnológicas que viabilizam o processo de ensino-aprendizagem para humanos, ou dispositivos tecnológicos que, por meio da memorização, podem “aprender” e, assim, redirecionar suas atividades/procedimentos).

- Cultivar e manter conexões é necessário para facilitar a aprendizagem contínua. A habilidade de enxergar conexões entre áreas, ideias e conceitos é uma habilidade fundamental. A circulação (conhecimento pre- 
ciso e atual) é a meta de todas as atividades de aprendizagem conectivistas.

- Tomar decisões é por si só um processo de aprendizagem. Escolher o que aprender e o significado das informações que chegam envolve um processo que sempre deverá ser visto através das lentes de uma realidade em mudança. Uma resposta certa agora pode ser errada amanhã devido a alterações no clima de informações que afetam a decisão.

De acordo com a teoria conectivista, a aprendizagem é considerada um processo no qual o papel da troca de informações organizadas em redes e apoiadas por ferramentas eletrônicas torna-se cada vez mais significativo. Aprender se torna um eterno e contínuo sistema de atividades incorporadas a outras atividades na rede.

A motivação para ganhar e contextualizar informação se torna mais forte se a pesquisa e a avaliação acontecem em cooperação na Web. Assim, o conhecimento coletivo, uma vez mais, se torna uma fonte de conhecimento individual. Conforme aumenta o número de atividades cooperativas, redes sociais tornam-se palco de troca informal de conhecimentos e "comunidades de prática" se desenvolvem. Além das questões de "como" e "o que" aprender, agora temos a questão do "onde aprender".

Por isso, os educadores que trabalham com modelos online têm aplicado o conectivismo em ensino e aprendizagem muito antes do surgimento da teoria formal conectivista. Nesse contexto, a Web ajuda a construir um tecido rico que combina os pequenos esforços de muitos com os grandes esforços de poucos. Ao enriquecer a diversidade de informações e conhecimentos disponíveis, permite que a cultura e a sensibilidade de uma região se modifiquem. De fato, sua mensagem é que a aprendizagem pode e deve estar acontecendo em todos os lugares - uma ecologia de aprendizagem. Ao mesmo tempo, um novo sistema autocatalítico começa a surgir, reforçando e alargando as competências essenciais de uma região, determinada pela apropriação do capital também na educação.

Portanto, faz-se possível afirmar que o conectivismo apresenta componentes de uma ecologia de aprendizado dinâmica e viva: informal e não estruturada. Assim, o sistema educacional não deveria definir a aprendizagem e a discussão antes do acontecimento (momento do ensino-aprendizagem) em si. Ao invés disso, o sistema deveria ser suficientemente flexível para permitir aos 
participantes criarem as discussões necessárias de acordo com suas necessidades. Para criar uma ecologia de compartilhamento de conhecimentos, os participantes precisam ver um ambiente em evolução consistente, baseado na confiança e no contato social elevado (face a face ou online), necessário para fomentar, igualmente, um sentimento de confiança e conforto.

\section{Alguns apontamentos Baseados em Pesquisa}

Para finalizar este artigo, apresentam-se algumas reflexões baseadas em pesquisa de doutorado recentemente concluída, que tomou como objeto um curso em modalidade online em nível de formação superior. ${ }^{3}$ Privilegiam-se as análises e implicações relativas ao papel docente nessa modalidade de ensino.

Dos resultados dessa investigação, cuja principal questão dizia respeito à possibilidade de o ensino online atender as necessidades atuais da educação e fornecer ao estudante o estímulo necessário ao processo de aprendizagem, o que se pôde abstrair foi que existem algumas premissas fundamentais para o êxito dessa modalidade educacional. Entre as principais, estão os recursos que o ambiente virtual do curso oferece, bem como a interação e a colaboração entre os alunos e o papel desempenhado pelo professor nesse ambiente. Esses elementos constituem o alicerce da educação online, pois é por meio deles que ocorre a ação educativa.

A pesquisa aponta que a grande preocupação da educação online envolve o professor, considerando sua conduta, seu preparo, sua disponibilidade e sua participação na aprendizagem do aluno. Além disso, aparecem outros elementos específicos do papel docente nesse modelo de aprendizagem, como a habilidade com a tecnologia do curso, a agilidade nas respostas em tempo real ou assíncrono, o retorno às tarefas elaboradas pelos alunos nos fóruns e a capacidade de incentivar o aluno a participar das discussões e pesquisas. Esses apontamentos tangem à interação efetiva professor-aluno, na qual se revela a importância da mediação, indicando que o papel do professor é tão importante nesse modelo de ensino como na educação presencial, podendo ser até mais central e oneroso do que o papel do professor no ensino tradicional.

Interessante destacar que a pesquisa demonstrou que a interação online entre os estudantes no âmbito do curso trouxe ganhos quanto ao sentimento 
de presença social, o que favoreceu o estabelecimento de uma comunidade de partilha bem como a construção coletiva de conhecimentos. Assim, há indícios fortes de que o ensino online é capaz de realçar a importância do aluno, para si próprio, fazendo que ele se sinta presente socialmente e parte de um todo, e atue com noção de cidadania para o grupo, colaborando com a formação de uma comunidade virtual de aprendizagem.

Ocorre, de fato, um panorama de colaboração alicerçado pelas redes na educação online. No entanto, a recente utilização dos ambientes virtuais na educação indica que não é por meio da inovação de uma ferramenta que a utilização massiva passa a permear a sociedade, mas a partir do momento em que a população se torna capaz de assimilar a tecnologia durante o uso cotidiano. Por isso, faz-se necessário o desenvolvimento de estratégias pedagógicas com o intuito de ampliar o letramento digital dos estudantes, para que a tecnologia seja uma interface virtualizada de novas possibilidades comunicacionais e educativas. Nesse sentido, o trabalho ratificou a integração multimídia da educação online como um elemento singular dessa modalidade de ensino, capaz de construir grupos por meio da conversação "muitos para muitos".

Vale a pena concluir destacando que o sentimento de pertencer e de ser acolhido num grupo constitui necessidade humana e requer cuidados para que seja possibilitado em qualquer modalidade de ensino. A educação online possibilita uma nova forma de construir coletivamente, de maneira multimídia e colaborativa. O professor, por meio das tecnologias digitais, é quem exerce a função de mediador, ao provocar os alunos a colaborarem na solução de tarefas de interesse comum e ao facilitar a interação com ele e com os pares. Isso ocorrendo num ambiente digital, onde há um claro deslocamento dos agentes de ensino para as questões a serem discutidas em que se criam resoluções coletivas em um imenso hipertexto, pautado em vários sistemas de proximidade que coexistem para constituir formas contemporâneas de ensinar e de aprender.

\section{REFERÊNCIAS}

BRAGLIA, Israel. O abolicionismo escolar: reflexões a partir do adoecimento e da deserção dos professores. Dissertação (Mestrado) - Faculdade de Educação, Universidade de São Paulo. São Paulo, 2012.

DOMINGUES, Diana. Dispositivos interativos: imagens los redes telemáticas. In: 
(Org.) Uma arte não XXI Século: a humanização das tecnologias. São Paulo: Ed. Unesp, 1997. p.295-302.

FREIRE, Paulo. Educação e mudança. São Paulo: Paz e Terra, 2011.

GALASSO, Bruno José Betti. Do ensino em linha ao ensino online: perspectivas para a educação online baseada na mediação professor-aluno. Tese (Doutorado em Educação) - Faculdade de Educação, Universidade de São Paulo, São Paulo, 2013. Disponível em: http://www.teses.usp.br/teses/disponiveis/48/48134/tde11122013-152402/; Acesso em: 21 abr. 2014.

GARRISON, D. R.; ANDERSON, T. El e-learning en el siglo XXI: investigación y práctica. Barcelona: Octaedro, 2005.

GROOMS, L. Interaction in the computer mediated adult distance learning environment: Leadership development through on-line distance education. Virginia Beach, VA: Regent University Press, 2000.

GUNWARDENA, C. N.; MCISAAC, M. S. Distance education. In: JONASSEN, D. H. (Ed.) Handbook of research for educational communication and technology. New Jersey: Lawrence Erlbaum. 2004. p.355-395.

HARASIM, L. Shift happens: online education as a new paradigm in learning. The Internet and Higher Education, v.3, n.1-2, p.41-61, 2000.

KEEGAN, Desmond. Foundations of distance education. 3.ed. London: Routledge, 1996.

LITTO, Fredric M. (Org.) Distance learning in Brazil: best practices 2006. São Paulo: Pearson Prentice Hall, 2006.

MACHADO, Arlindo. O quarto iconoclasmo e outros ensaios hereges. Rio de Janeiro: Rios Ambiciosos, 2001.

MEDEIROS, M. Fotografia e narcisismo: o auto-retrato contemporâneo. Lisboa: Assírio \& Alvim, 2000.

MELO, Maria T. de; CARVALHO NETO, Cassiano Z.; SPANHOL, Fernando J. (Org.) Hipermídias: interfaces digitais em EaD. São Paulo: Laborciência, 2009.

MOLINA, Rinaldo. A pesquisa-ação/investigação-ação no Brasil: mapeamento da produção (1966-2002) e os indicadores internos da pesquisa-ação colaborativa. Tese (Doutorado) - Faculdade de Educação, Universidade de São Paulo. São Paulo, 2007.

MOORE, M. G. Distance education theory. The American Journal of Distance Education, v.5, n.3, 1991.

NEUMAN, S.; ROSKOS, K. Literacy Knowledge in Practice: Contexts of Participation for Young Writers and Readers. Reading Research Quarterly, v.32, n.1, p.10-33, 1997. 
OGLIARI, Celso L.; SOUZA, Márcio V. de. EaD e os Desafios das Novas Tecnologias: LabMídia da UFSC - Campus Araranguá, uma experiência de apoio à educação em rede. In: SEMINÁRIO DE PESQUISA EM EAD, 4.: Experiência e Reflexões. Araranguá: UFSC, 2012. (Mimeo.)

ROCKWELL, E. La appropiación, un proceso entre muchos que ocurren en ámbitos escolares. Memoria, conocimiento y utopia: anuário de la sociedad Mexicana de Historia de la educación, Barcelona: Ed. Pomares, n.1, enero 2004-maio 2005.

SALATINO, A. T. Entre laços e redes de sociabilidade: sobre jovens, celulares e escola contemporânea. Dissertação (Mestrado) - Faculdade de Educação, Universidade de São Paulo. São Paulo, 2014.

SIEMENS, G. Connectivism: A Learning Theory for the Digital Age. elearnspace, Dec. 2004. Disponível em: http://www.elearnspace.org/Articles/connectivism.htm; Acesso em: 3 maio 2011.

SIEMENS, G. Learning Ecology, Communities, and Networks: Extending the Classroom, elearnspace, 2003. Disponível em: http://www.elearnspace.org/Articles/learning_communities.htm.

TOFFLER, A. Powershift: as mudanças do poder. Rio de Janeiro: Record, 1990.

TORRICELLI, Camila; CORREA, Andreia. In: SIED, Simpósio Internacional de Educação a Distância / ENPED, Encontro de Pesquisadores em Educação a Distância. São Carlos, SP, Universidade Federal de São Carlos, set. 2012. (Mimeo.)

\section{NOTAS}

${ }^{1}$ Permeabilidade é uma noção trazida por Elsie Rockwell (2005) ao apresentar sua concepção de escola.

${ }^{2}$ Ver A. T. Salatino (2014, p.198), interessante trabalho de pesquisa sobre como adolescentes e jovens das camadas populares constroem sua experiência escolar em um contexto cotidiano marcado pela disseminação de aparelhos tecnológicos.

${ }^{3}$ Trata-se da disciplina de Tecnologia Educativa (60h/a) do curso de mestrado e doutoramento em Ciências da Educação da Universidade do Minho que, criado em 1982, conta com as seguintes áreas de especialização: Análise e Organização de Ensino, Ensino das ciências da Natureza e Ensino da Língua Portuguesa. Mais detalhes sobre a disciplina e esse estudo de caso estão disponíveis no capítulo 3 da tese de doutorado do presente autor (GALASSO, 2013).

Artigo recebido em 30 de maio de 2014. Aprovado em 27 de junho de 2014. 